\title{
Secondary analysis of an RCT on Emergency Department Initiated Tobacco Control: Repeatedly assessed point-prevalence abstinence up to 12 months and extension of results through a 10-year follow-up
}

\author{
Edith Weiss-Gerlach', William J. McCarthy², Jürgen Wellmann³, Marie Graunke', Claudia Spies' ${ }^{1}$, Bruno Neuner ${ }^{1}$
}

\begin{abstract}
INTRODUCTION Emergency departments (EDs) are opportune places for tobacco control interventions. The 'Tobacco Control in an Urban Emergency Department' (TED) study, ISRCTN41527831, originally evaluated the effect of motivational interviewing on-site plus up to four booster telephone calls on 12-month abstinence. This study's aim was to evaluate the effect of the intervention on 7-day point-prevalence abstinence at 10 years follow-up (primary outcome) as well as on repeated point-prevalence abstinence at 1, 3, 6, 12 months and at 10 years (continual smoking abstinence, secondary outcome).

METHODS At the 10 years follow-up and after informed consent, study participants responded to a mailed questionnaire. The primary outcome was analyzed in observed-only and in all-cases analyses. The secondary outcomes were analyzed using a multiple adjusted GLMM for binary outcomes.

RESULTS Out of 1012 TED-study participants, 986 (97.4\%) were alive and 231 (23.4\% of 986) responded to the follow-up at 10 years. For observed-only and all-cases analyses, the effect of the baseline intervention on 7-day point-prevalence abstinence at the 10 years follow-up was statistically non-significant. However, when taking into account all repeated measures, the intervention significantly influenced continual abstinence with odds ratio 1.32 (95\% CI: 1.01-1.73; $\mathrm{p}=0.042$ ). Baseline motivation, perceived self-efficacy to stop smoking, and nicotine dependency were independently associated with long-term continual smoking abstinence (all $\mathrm{p}<0.05$ ).

CONCLUSIONS A conventional analysis failed to confirm a significant effect of the EDinitiated tobacco control intervention on the point-prevalence abstinence at 10 years. Results from a more integrative analysis nonetheless indicated an enduring intervention effect on continual abstinence among smokers first encountered in the emergency department setting 10 years earlier.
\end{abstract}

ABBREVIATIONS GLMM: generalized linear mixed model, TED: Tobacco Control in an Urban Emergency Department, ED: emergency department, RCT: randomized controlled trial, Laocoon: Long-Term-Follow-up of Tobacco Control in an Urban Emergency Department

\section{INTRODUCTION}

Emergency departments (EDs) are opportune settings for promoting healthier lifestyle behaviors and preventing disease, including cigarette smoking ${ }^{1,2}$.

\author{
AFFILIATION \\ 1 Department of \\ Anesthesiology and Intensive \\ Care Medicine, Charité- \\ Universitätsmedizin Berlin, \\ Berlin, Germany \\ 2 Center for Cancer \\ Prevention and Control \\ Research, UCLA Fielding \\ School of Public Health, Los \\ Angeles, United States \\ 3 Institute of Epidemiology \\ and Social Medicine, \\ University of Münster, \\ Münster, Germany

\section{CORRESPONDENCE TO} \\ Bruno Neuner. Charité- \\ Universitätsmedizin Berlin, \\ Charitéplatz 1, 10117 Berlin, \\ Germany. E-mail: bruno. \\ neuner@charite.de \\ KEYWORDS \\ tobacco use cessation, \\ emergency service, hospital, \\ long-term follow-up
}

Received: 21 December 2018 Revised: 8 March 2019

Accepted: 12 March 2019
A 2006 recommendation of the American College of Emergency Physicians advocated routine screening of ED patients' smoking status and to advise ED smokers to quit $^{3}$. The recommendation introduced the term 
'Emergency Department-Initiated Tobacco Control' for such procedures, typically a combination of onsite motivational interviewing/counseling, followed by either booster interventions or referral to other institutions providing smoking cessation counseling ${ }^{3}$. Since 2000, several randomized controlled trials (RCTs) evaluated the efficacy of such screening and brief intervention efforts, mostly a combination of an initial motivational counselling session and either booster intervention sessions or referral to outpatient services, including tobacco quitlines. A recent systematic review and meta-analysis identified 11 RCTs and a significant effect of EDinitiated tobacco control on 7-day point-prevalence tobacco abstinence at 1 and 3 months follow-up ${ }^{4}$. Additionally, a statistically significant benefit from exposure to the ED-initiated tobacco control services was observed, using repeated 7-day point-prevalence tobacco abstinence measures (continual tobaccouse abstinence) up to 12 months post-intervention. Pooling the results of all available studies and across all follow-up time points, patients in the intervention group showed a relative risk (RR) of 1.40 (95\% CI: $1.06-1.86 ; p=0.02)$, of being tobacco abstinent ${ }^{4}$. Thus, their chance of being at least momentarily abstinent increased by $40 \%$. Continual tobacco-use abstinence may be regarded as an important precursor to continuous abstinence, the ultimate goal of tobacco cessation efforts for several reasons: 1) even transient periods of smoking abstinence may yield positive health impact, for example, on lung function ${ }^{5}$; 2) previous experience with temporary abstinence predisposes to further attempts to quit ${ }^{6}$; and 3 ) smokers typically need several quit attempts before achieving long-term abstinence ${ }^{7}$. The aim of the current study was therefore two-fold: First, a 10-year follow-up allowed us to evaluate the long-term outcome of an ED-initiated tobacco control intervention 10 years after the initial RCT was stopped ${ }^{8}$. Secondly, by evaluating continual abstinence instead of the 7-day point-prevalence tobacco abstinence at the 12 months follow-up, we re-evaluated the initial RCT on ED-initiated tobacco control ${ }^{8}$ and extended the analysis of continual abstinence status to follow-up over 10 years. Finally, the multivariable analysis of these parameters allowed the identification of baseline parameters independently associated with long-term continual abstinence.

\section{METHODS}

\section{Data sources}

The parent study was the randomized, controlled trial entitled 'Tobacco Control in an Urban Emergency Department' (TED), ISRCTN41527831 ${ }^{8}$. This single-center study was conducted in $2005 / 2006$ at one campus of the Charité-Universitaetsmedizin Berlin, Germany, with the last follow-up taking place in January 2008. The emergency department at this campus has two subunits, one for surgical and one for internal medicine patients. The study was conducted in both units. Briefly, 1012 out of 1044 randomized urban emergency department patients had a complete baseline assessment and received either motivational interviewing on-site in combination with up to four booster phone calls, or usual care. Usual care patients received a brief leaflet with some general information on smoking cessation but no counselling on-site and no booster phone calls. Follow-up assessment started one month after the motivational interviewing on-site and was repeated at 3,6 , and 12 months followup. The predefined outcome was the 7 -day pointprevalence abstinence at the 12 months follow-up, showing an adjusted intervention effect versus usual care $(\mathrm{OR}=1.31 ; 95 \% \text { CI: } 0.91-1.89 ; \mathrm{p}=0.15)^{8}$.

\section{Ten-year follow-up}

The 'Long-Term-Follow-up of Tobacco Control in an Urban Emergency Department' (Laocoon) study received ethical committee approval (EA1/238/15) in June 2015. Out of 1012 TED-study participants with complete baseline questionnaire, $122(12.1 \%)$ were not reachable at the follow-up at 12 months. Thus, initially 890 study participants received a mailed 'study package', consisting of the study information, the consent form and the study questionnaire together with a business reply envelope. Successively undeliverable mailing addresses, together with the 122 addresses known to be incorrect were transferred to Address Research ${ }^{\circledR}$, a service provider from the German postal service (Deutsche Post AG). This service provider has access to official registration office data and provides information on national addresses, information on tenancy changeover abroad (with no further information on target country or a specific address) and, in case of death, information on the mortality status. Newly retrieved addresses 
were continuously added into the contact algorithm. Study participants of the TED study, who were alive at the time of the Laocoon study and who had a known current address received the initial study package and two postal reminders. A last attempt was made to reach potential eligible participants by sending a 2-page questionnaire, evaluating the main study outcome.

\section{Study measures}

All study measures were evaluated by selfadministered postal questionnaire. The predefined primary outcome was the 7-day point-prevalence abstinence at the 10 years follow-up. This outcome was assessed using two questions: 'Did you smoke during the past seven days?'. Those, who answered 'daily' or 'on xx days', were asked: 'During the days on which you smoked, how many cigarettes did you usually smoke per day?'. Further smoking-status related questions concerned the degree of nicotine dependency, measured with the Fagerström Test for Nicotine Dependency (FTND) ${ }^{9}$, motivation to stop smoking, assessed with a single question 'When do you wish to stop smoking?' with three possible answers: 'Not within the next 6 months'=unmotivated smokers,
'Within the next 6 months but not within the next 4 weeks' $=$ ambivalent smokers and 'Within the next 4 weeks' $=$ motivated smokers ${ }^{10,11}$. Further questions evaluated illicit drug use ${ }^{8}$, alcohol consumption ${ }^{12}$, socioeconomic status ${ }^{8}$ and the participant's current medical status. The 2 -page questionnaire evaluated the main study outcome, the heaviness of smoking index $\left(\mathrm{HSI}^{13}\right.$, a short-form of the FTND ${ }^{9}$ ), motivation to stop smoking ${ }^{10,11}$ and current medical status.

A secondary study outcome was repeated pointprevalence abstinence through 10 years of follow-up (i.e. 7-day point-prevalence tobacco abstinence at 1 , $3,6,12$ months and at 10 years, continual abstinence). Covariates for adjustments of the multivariable models (see Statistical Analysis section) were chosen based on their association $(\mathrm{p}<0.1)^{14,15}$ with participant nonresponse (Table 1) or because the scientific literature had identified them as recognized predictors of smoking counseling outcomes, these were: emergency department subunit (surgical or internal medicine), age, level of nicotine dependency (Fagerström Test), partnership status, educational level (universityentrance diploma), having a family doctor, gender, motivation to stop smoking (10-point scale from 1 to 10 points according to Miller and Rollnick ${ }^{16}$ ) and

Table 1. Predictors of repeated point prevalence abstinence up to $12 \mathrm{months}$ and up to 10 years after emergency department-initiated tobacco control, results of GLMM analyses $(\mathrm{N}=1011)^{\text {a }}$

\begin{tabular}{|c|c|c|c|c|c|c|}
\hline \multirow[t]{2}{*}{$\begin{array}{l}\text { Baseline parameter at study entry } \\
\text { (TED study) }\end{array}$} & \multicolumn{3}{|c|}{$\begin{array}{l}\text { Vodel 1: Follow up through } 12 \\
\text { months only }\end{array}$} & \multicolumn{3}{|c|}{ Vodel 2: Follow up through 10 years } \\
\hline & & OR $\left(95^{\circ} \circ \mathrm{CI}\right)$ & $p$ & & OR $\left(95^{\circ} \circ \mathrm{CI}\right)$ & p \\
\hline Intervention group vs control group & unadjusted $^{b}$ & $1.32(0.99-1.77)$ & 0.062 & unadjusted $^{b}$ & $1.32(1.02-1.72)$ & 0.035 \\
\hline Intervention group vs control group & adjusted $^{c}$ & $1.28(0.95-1.74)$ & 0.103 & adjusted $^{c}$ & $1.32(1.01-1.73)$ & 0.042 \\
\hline Internal medicine subunit vs surgical subunit & & $1.42(1.04-1.93)$ & 0.027 & & $1.32(1.01-1.74)$ & 0.044 \\
\hline Age (years), per additional year & & $1.01(0.99-1.02)$ & 0.40 & & $1.01(0.99-1.02)$ & 0.36 \\
\hline Male vs Female gender & & $0.97(0.71-1.32)$ & 0.84 & & $0.93(0.71-1.23)$ & 0.63 \\
\hline Fagerström test, per additional point & & $0.88(0.82-0.95)$ & 0.001 & & $0.89(0.83-0.94)$ & $<0.001$ \\
\hline Motivation to stop smoking ${ }^{d}$, per additional point & & $1.20(1.13-1.28)$ & $<0.001$ & & $1.19(1.13-1.25)$ & $<0.001$ \\
\hline $\begin{array}{l}\text { Perceived self-efficacy to stop smoking }{ }^{\mathrm{e}} \text {, per } \\
\text { additional point }\end{array}$ & & $1.18(1.11-1.26)$ & $<0.001$ & & $1.15(1.09-1.22)$ & $<0.001$ \\
\hline \multicolumn{7}{|l|}{ Partnership } \\
\hline Non-smoking partner vs no partnership & & $1.03(0.71-1.50)$ & 0.87 & & $1.17(0.84-1.62)$ & 0.36 \\
\hline Smoking partner vs no partnership & & $0.73(0.51-1.05)$ & 0.087 & & $0.74(0.54-1.03)$ & 0.071 \\
\hline University-entrance diploma vs none & & $1.17(0.86-1.60)$ & 0.32 & & $1.21(0.92-1.60)$ & 0.17 \\
\hline Family doctor vs none & & $1.11(0.79-1.57)$ & 0.55 & & $1.16(0.85-1.58)$ & 0.34 \\
\hline
\end{tabular}

a1012 participants of the TED study with complete baseline questionnaire data minus one study participant who withdrew his initial participation consent. b With time to follow-up as ordinal term and interaction intervention groupxtime linear ( $p>0.9)$. c Plus adjustments. $d$ 10-point scale from 1 to 10 points with higher points indicating higher motivation to stop smoking ${ }^{16}$. e10-point from 1 to 10 points with higher points indicating higher perceived self-efficacy to stop smoking ${ }^{17}$. TED: Tobacco Control in an Urban Emergency Department ${ }^{8}$. GLMM: generalized linear mixed model. OR: odds ratio. Cl: confidence interval. 
perceived self-efficacy to stop smoking (10-point scale from 1 to 10 points according to Miller and Rollnick ${ }^{17}$ ). The lower pole of the two scales referred to no motivation/no self-efficacy to stop smoking while the upper pole indicated very high motivation/ self-efficacy to stop smoking.

\section{Statistical analysis}

The patients' flow through the follow-up is graphically displayed by a lasagna-plot ${ }^{18}$, a way of showing for all study participants the individual course of smoking/ non-smoking and study attrition transitions over all follow-up times.

Binary and ordinal variables are depicted as absolute and relative numbers. For variables with normal distributions, the measures of central tendency used are means with standard deviations, while for non-normally distributed variables, medians and their ranges are used. Differences between two independent groups were evaluated in normally distributed variables and non-normally distributed variables using Student's t-test and Mann-Whitney-UTest, respectively. For binary data such as the primary outcome of the Laocoon study (current smoking/nonsmoking status), comparisons between groups were done using the chi-squared test.

The secondary study outcome, the effect of the EDinitiated tobacco control intervention on continual abstinence assessed repeatedly until the assessment at 12 months (totaling four follow-up times) and assessment at 10 years (thus totaling five followup times), was analyzed by logistic regression for repeated, correlated binary outcomes (generalized linear mixed models, GLMMs). The GLMM accounts for heterogeneity in the effect of the initial tobacco control intervention between subjects as well as for heterogeneity in the effect over time. A Markovtype Ante-Dependence covariance structure ${ }^{19,20}$ was employed for the marginal covariance matrix of each participant, which entails four and five different variance parameters, until 12 months (fourth followup) and until 10 years (fifth follow-up), respectively. This approach avoids repeated single tests of repeated measurements without taking the correlation with the preceding measurement and the preceding test statistics into account ${ }^{19}$. It is reasonable to assume a decaying correlation structure between repeated pairs of measurements over successive assessment intervals and thus a fading-off of the initial tobacco control intervention over time. Therefore, three (12-month follow-up, Model 1 in Table 1) and four (10-year follow-up, Model 2 in Table 1) additional covariances were included to capture the variability attributable to the transition from one follow-up examination to the next and to capture the varying time intervals between consecutive follow-up assessments (between one month and nine years). These correlations may be estimated from the data and are shown in Supplementary Table 1. The Ante-Dependence covariance structure is also robust in settings with dropouts unrelated to the "treatment" ${ }^{\text {"19 }}$, i.e. the tobacco cessation counseling in this study (Table 2; eligibility at 10 years was not associated with randomization status). The randomly assigned treatment group at baseline, time of follow-up assessment (one, three, six and twelve months as well as 10 years after baseline), and their interaction term were entered into the model as categorical variables. The interaction term was meant to capture an eventual differential effect of time in both study arms. The interpretation of the main effect of the intervention is that of an overall effect of the treatment across all time-points. The model was formulated using 'Proc glimmix' in SAS and the Ante-Dependence covariance structure was defined using the random statement:

RANDOM time $/$ subject $=$ id type $=$ ante $(1)$ RESIDUAL .

Although the baseline data were derived from a well-balanced RCT with no indication of residual confounding (see Table 1 of Nuener et al. ${ }^{8}$ ), an unadjusted model was considered to be a suboptimal solution to modeling effects over such a long time span. Adjusting for variables associated with loss to follow-up was meant to address potential biases caused by differential attrition.

A p-value of less than 0.05 was defined as statistically significant. All statistical analyses were run in SPSS (IBM SPSS Statistics for Windows, Version 25.0. Armonk, NY: IBM Corp) or in SAS University Edition ${ }^{\circledR}$.

\section{RESULTS}

Out of 1012 TED-study participants with complete baseline questionnaire, $986(97.3 \%)$ were potentially eligible for participation in the Laocoon study. Correct addresses were identified for 685 study participants $(69.5 \%)$ and of these, 231 (33.7\% of the 685$)$ 
Table 2. Baseline characteristics at the time of inclusion in the TED study in Laocoon-study participants, Laocoon-study non-responder and patients with indeterminate postal address ( $\mathrm{N}=986)$

\begin{tabular}{|c|c|c|c|c|}
\hline \multirow{2}{*}{$\begin{array}{l}\text { Baseline and follow up measures } \\
\text { (TED study) }\end{array}$} & \multicolumn{3}{|c|}{ Current determinate postal address } & \multirow{2}{*}{$\begin{array}{l}\text { Indeterminate } \\
\text { postal address } \\
\text { N } 301\left(30.5^{\circ} \%\right)\end{array}$} \\
\hline & $\begin{array}{l}\text { Study participants } \\
\text { V } 231\left(23.1^{\circ} \%\right)\end{array}$ & $\begin{array}{l}\text { Von responder } \\
\mathbf{N}=\mathbf{1 5} 1\left(16.0^{\circ} \%\right)\end{array}$ & p & \\
\hline Intervention group, $\mathrm{n}(\%)$ & $119(51.5)$ & $214(47.1)$ & 0.28 & $160(53.2)$ \\
\hline Surgical subunit of the ED, $\mathrm{n}(\%)$ & $125(54.1)$ & $214(47.1)$ & 0.084 & $137(45.5)$ \\
\hline Non-smoker at 1 month follow-up $(\mathrm{N}=654)$ n $(\%)$ & $17(9.5)$ & $21(7.3)$ & 0.39 & $19(10.2)$ \\
\hline Non-smoker at 3 months follow-up $(\mathrm{N}=621)$ n $(\%)$ & $25(14.0)$ & $33(11.7)$ & 0.48 & $23(14.3)$ \\
\hline Non-smoker at 6 months follow-up $(\mathrm{N}=633)$ n $(\%)$ & $35(18.9)$ & $49(16.9)$ & 0.57 & $27(17.1)$ \\
\hline Non-smoker at 12 months follow-up $(\mathrm{N}=671)$ n $(\%)$ & $47(23.6)$ & $49(15.9)$ & 0.031 & $33(20.1)$ \\
\hline Age (years) mean $\pm S D$, range & $34.9 \pm 12.0,(18-68)$ & $31.9 \pm 9.9,(18-73)$ & 0.001 & $30.9 \pm 9.3,(18-78)$ \\
\hline Female gender, $\mathrm{n}(\%)$ & $103(44.6)$ & $174(38.3)$ & 0.14 & $111(36.9)$ \\
\hline Number of cigarettes smoked per day mean $\pm S D$, range & $15.0 \pm 9.3,(1-40)$ & $16.9 \pm 9.5,(1-60)$ & 0.013 & $17.0 \pm 10.3,(1-60)$ \\
\hline Fagerström test mean \pm SD & $2.9 \pm 2.6$ & $3.4 \pm 2.5$ & 0.019 & $3.6 \pm 2.6$ \\
\hline Motivation to stop smoking 10 -point scale, mean \pm SD & $5.4 \pm 2.7$ & $5.7 \pm 2.6$ & 0.12 & $5.7 \pm 2.5$ \\
\hline \multicolumn{5}{|l|}{ Motivation to stop smoking ${ }^{\mathrm{a}}, \mathrm{n}(\%)$} \\
\hline unmotivated & $135(58.4)$ & $253(55.7)$ & & $151(50.2)$ \\
\hline ambivalent & $66(28.6)$ & $143(31.5)$ & $0.66^{c}$ & $111(36.9)$ \\
\hline motivated & $30(13.0)$ & $58(12.8)^{b}$ & & $39(13.0)^{b}$ \\
\hline $\begin{array}{l}\text { Perceived self-efficacy to stop smoking 10-point scale, } \\
\text { mean } \pm \text { SD }\end{array}$ & $5.6 \pm 2.9$ & $5.5 \pm 2.7$ & 0.12 & $5.6 \pm 2.6$ \\
\hline Harmful alcohol consumption ${ }^{d}$, n (\%) & $81(35.1)$ & $150(33.0)$ & 0.60 & $107(35.5)$ \\
\hline Illicit drug use ${ }^{\mathrm{e}}$, n (\%) & $127(55.0)$ & $250(55.1)$ & 0.98 & $192(63.8)$ \\
\hline \multicolumn{5}{|l|}{ Partnership, n (\%) } \\
\hline Non-smoking partner & $73(31.6)$ & $123(27.1)$ & 0.089 & $78(25.9)$ \\
\hline Smoking partner & $87(37.7)$ & $211(46.5)$ & & $130(43.2)$ \\
\hline No partner & $71(30.7)$ & $120(26.4)$ & & $93(30.9)$ \\
\hline Living in a single household, $\mathrm{n}(\%)$ & $87(37.7)$ & $165(36.3)$ & 0.74 & $123(40.9)$ \\
\hline University-entrance diploma, n (\%) & $128(55.4)$ & $206(45.4)$ & 0.013 & $156(51.8)$ \\
\hline $\begin{array}{l}\text { Net family income/month above median in } 2006 \\
(\mathrm{~N}=187) \mathrm{n}(\%)\end{array}$ & $72(38.5)$ & $138(41.7)$ & 0.48 & $80(34.5)$ \\
\hline Family doctor, n (\%) & $183(79.2)$ & $330(72.7)$ & 0.062 & $189(62.8)$ \\
\hline
\end{tabular}

a 'When do you wish to stop smoking?' ('Not within the next 6 months'=unmotivated smokers, 'Within the next 6 months but not within the next 4 weeks'=ambivalent smokers and 'Within the next 4 weeks'=motivated smokers) ${ }^{10,11}$. b Does not sum up to $100 \%$ because of rounding error. c Chi-squared test for trend; $d \geq 5$ points in the AUDIT-PC'2. e At least one single use within the last 12 months before the TED-study baseline: cannabis, ecstasy, other designer drugs, natural drugs (e.g. Peyote), cocaine, morphine, heroin or other opiates ${ }^{8}$. f $1475 € /$ month $^{8}$. TED: Tobacco Control in an Urban Emergency Department ${ }^{8}$. SD: standard deviation. ED: emergency department. AUDIT-PC: Alcohol Use Disorders Identification Test-Piccinelli Consumption.

participated in the 10-year follow-up. Seventy-four study participants $(32.0 \%$ of the 231$)$ returned only the brief 2-page questionnaire. The details of the study participation/non-participation over time are shown in Figure 1.

The lasagna-plot (Figure 2) shows the large proportion of those already lost to follow-up at 1 month (the white space above the second bar). However, with increasing duration of follow-ups and additional follow-up assessments, around two-thirds of those lost to follow-up at the assessment at 1 month ended up providing follow-up information about their smoking status at least one additional time. This held true even for those who were lost to follow-up between the 1 and 3 months follow-up assessments. Thus, over the course of the initial study period with a 12 -month follow-up, more than $85 \%$ of study participants provided follow-up information at 
Figure 1. Flowchart of the study participation process $(n=1012)$

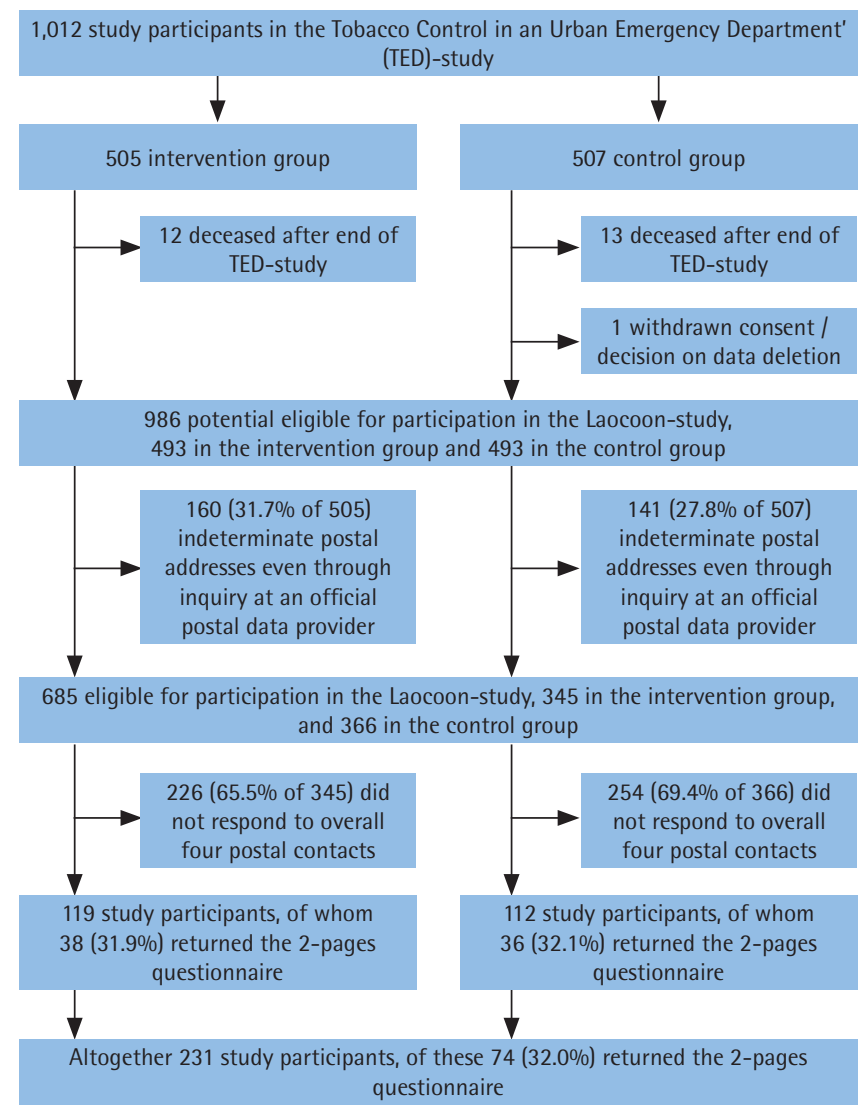

least once. On the other hand, many study participants who participated in the first follow-up assessment at one month did not provide further information or provided incomplete information in later follow-up assessments.

Regarding smoking status over consecutive assessments, only 7 out of $986(0.7 \%)$ study participants were tobacco abstinent at all followup assessments and presumably stopped smoking permanently after the initial smoking cessation intervention. These 7 are represented on the lasagnaplot by the continual blue part of the five follow-up charts culminating in the sliver of blue at the bottom of the 6th assessment. Only 55 out of 986 (5.6\%) study participants completed follow-up information indicating continual smoking at every assessment. These 55 are represented by the largest red 'slice' one-fifth from the bottom of the 5th follow-up assessment. Thus, nearly 94 per cent of study participants switched between smoking/non-smoking status and study participation/study attrition over the course of five assessments conducted over 10 years of follow-up.

The total number of non-smokers in both study groups and per follow-up interval is given in

Figure 2. Lasagna-plot and marginal distribution table of smoking status and dropouts over all follow-up assessments for the TED and Laocoon studies $(\mathrm{N}=1011)$

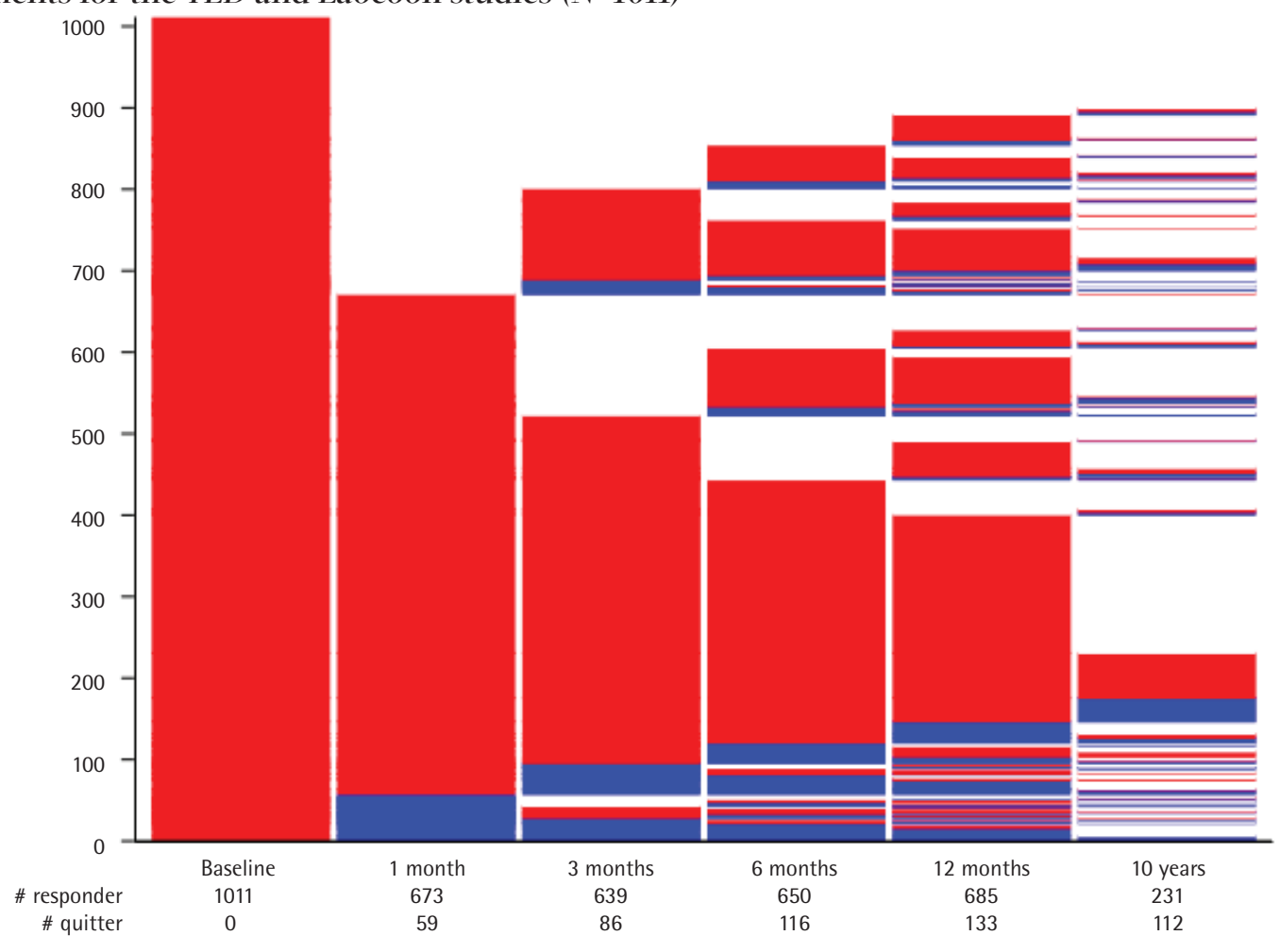


Supplementary Figure 1. The number of non-smokers in the intervention group exceeded the number of non-smokers in the control group at all follow-up assessments. The highest total numbers of nonsmokers occurred in both study groups at the 12 months follow-up. At the 10 years follow-up, in observed cases-only analysis, the total number of non-smokers (the primary outcome of the Laocoon study) was $61 / 119(51.3 \%)$ in the intervention group and $51 / 112(45.5 \%)$ in the control group, $p=0.38$. The corresponding all-cases analysis with penalized imputation (non-responder classified as current smoker) yielded $61 / 505$ (12.1\%) non-smokers in the intervention group and 51/506 (10.1\%) non-smokers in the control group, $\mathrm{p}=0.31$.

Table 1 shows the results after re-analyzing the continual abstinence (secondary study outcome of the Laocoon study). Through the 12 months followup (adjusted Model 1), the intervention showed an independent statistically non-significant effect $(\mathrm{OR}=1.28,95 \%$ CI $0.95-1.74 ; \mathrm{p}=0.103)$ but through the 10 years follow-up (adjusted model 2), the intervention showed a statistically significant effect $(\mathrm{OR}=1.32,95 \%$ CI 1.01-1.73, $\mathrm{p}=0.042)$ ( Table 1$)$. In this final model, other significant and independent associations of continual abstinence up to 10 years follow-up with baseline parameter were time to follow-up assessment $(\mathrm{p}<0.001$ in all four models), smoking-related factors such as higher points on a motivation ladder and higher perceived self-efficacy to stop smoking, as well as less nicotine dependence as measured with the Fagerström test. Patients in the internal medicine subunit of the ED had higher odds of becoming non-smokers compared to surgical patients from the surgical subunit $(\mathrm{p}=0.027$ up to 12 months follow-up and $\mathrm{p}=0.044$ up to 10 years followup, respectively). The covariance parameter estimates for this final model showed nearly identical variance for the five measures in each of the four models, respectively, and declining correlations between consecutive assessments (Supplementary Table 1).

Table 2 compares baseline characteristics of study participants in the 10 years follow-up (follow-up responder) with those of follow-up non-responders who did not respond to any of three contact attempts. Table 2 additionally provides information on the baseline characteristics of study participants with no current addresses identified. Neither exposure to the smoking intervention at baseline, nor the smoking status up to 6 months after the intervention is associated with 10-year loss to follow-up (all $\mathrm{p}>0.05)$. Higher abstinence rates at 12 months follow-up $(23.6 \%$ vs $15.9 \%, p=0.031)$ as well as older age at baseline $(\mathrm{p}<0.001)$, higher educational attainment $(p=0.013)$ and smoking fewer cigarettes per day $(p=0.013)$ at baseline and being less tobacco dependent $(p=0.019)$ at baseline were significantly associated with study participation at the 10 years follow-up.

Table 3 shows the baseline characteristics of the 231 Laocoon-study participants, stratified by smoking status at the 10 years follow-up. While there was no difference in randomization status $(p=0.38)$, those study participants who were tobacco-abstinent at the 10 years follow-up were smoking on average fewer cigarettes at baseline, were less nicotine

Table 3. Comparing 10-year non-smokers and current smokers in the Laocoon study on TED-study baseline characteristics $(\mathrm{N}=231)$

\begin{tabular}{|c|c|c|c|}
\hline $\begin{array}{l}\text { Baseline and follow up measures } \\
\text { (TED study) }\end{array}$ & $\begin{array}{l}\text { 10 Jear non-smoker } \\
\text { V } 112\left(18.5^{\circ} \%\right)\end{array}$ & $\begin{array}{l}10 \text { year smoker } \\
\text { V } 119(51.5 \%)\end{array}$ & $p$ \\
\hline Intervention group, $\mathrm{n}(\%)$ & $61(54.5)$ & $58(48.7)$ & 0.38 \\
\hline Surgical subunit of the ED, $\mathrm{n}(\%)$ & $66(55.5)$ & $59(52.7)$ & 0.67 \\
\hline Non-smoker at 1 month follow-up $(\mathrm{N}=179) \mathrm{n}(\%)$ & $14(16.3)$ & $3(3.2)$ & 0.003 \\
\hline Non-smoker at 3 months follow-up $(\mathrm{N}=179)$ n $(\%)$ & $20(25.0)$ & $5(5.1)$ & $<0.001$ \\
\hline Non-smoker at 6 months follow-up $(\mathrm{N}=185) \mathrm{n}(\%)$ & $23(25.8)$ & $12(12.5)$ & 0.021 \\
\hline Non-smoker at 12 months follow-up ( $\mathrm{N}=199) \mathrm{n}(\%)$ & $35(36.8)$ & $12(11.5)$ & $<0.001$ \\
\hline Age (years) mean $\pm S D$, range & $35.5 \pm 12.2,(18-65)$ & $34.3 \pm 11.8,(18-68)$ & 0.46 \\
\hline Female gender, n (\%) & $51(45.5)$ & $52(43.7)$ & 0.78 \\
\hline Number of cigarettes smoked per day mean $\pm S D$, range & $13.4 \pm 9.5,(1-40)$ & $16.5 \pm 8.9,(1-35)$ & 0.009 \\
\hline Fagerström test mean \pm SD & $2.5 \pm 2.5$ & $3.4 \pm 2.6$ & 0.008 \\
\hline Motivation to stop smoking 10 -point scale, mean \pm SD & $5.9 \pm 2.8$ & $5.0 \pm 2.6$ & 0.058 \\
\hline
\end{tabular}


Table 3. Continued

\begin{tabular}{|c|c|c|c|}
\hline $\begin{array}{l}\text { Baseline and follow up measures } \\
\text { (TED study) }\end{array}$ & $\begin{array}{l}\text { 10 year non-smoker } \\
\mathrm{N}-112(18.5 \%)\end{array}$ & $\begin{array}{l}\text { 10- Jear smoker } \\
\text { N-119 (51.5\%o) }\end{array}$ & $p$ \\
\hline \multicolumn{4}{|l|}{ Motivation to stop smoking ${ }^{\mathrm{a}}, \mathrm{n}(\%)$} \\
\hline unmotivated & $59(52.7)$ & $76(63.9)$ & \\
\hline ambivalent & $34(30.4)$ & $32(26.9)$ & $0.044^{c}$ \\
\hline motivated & $19(17.0)^{b}$ & $11(9.2)$ & \\
\hline Perceived self-efficacy to stop smoking 10 -point scale, mean \pm SD & $5.5 \pm 2.6$ & $5.4 \pm 2.9$ & 0.16 \\
\hline Harmful alcohol consumption ${ }^{d}, \mathrm{n}(\%)$ & $31(27.7)$ & $50(42.0)$ & 0.022 \\
\hline Illicit drug use ${ }^{e}, \mathrm{n}(\%)$ & $57(50.9)$ & $70(58.8)$ & 0.23 \\
\hline \multicolumn{4}{|l|}{ Partnership, $\mathrm{n}(\%)$} \\
\hline No partner & $31(27.7)$ & $40(33.6)$ & \\
\hline Smoking partner & $33(29.5)$ & $54(45.4)$ & 0.001 \\
\hline Non-smoking partner & $48(42.9)$ & $25(21.0)$ & \\
\hline Living in a single household, $\mathrm{n}(\%)$ & $38(33.9)$ & $49(41.2)$ & 0.26 \\
\hline University-entrance diploma, n (\%) & $70(62.5)$ & $58(48.7)$ & 0.035 \\
\hline Net family income/month above median ${ }^{f}$ in $2006(\mathrm{~N}=187)$ n (\%) & $31(33.3)$ & $41(43.6)$ & 0.15 \\
\hline Family doctor, $\mathrm{n}(\%)$ & $90(80.4)$ & $93(78.2)$ & 0.68 \\
\hline
\end{tabular}

a 'When do you wish to stop smoking?' ('Not within the next 6 months'=unmotivated smokers, 'Within the next 6 months but not within the next 4 weeks'=ambivalent smokers and 'Within the next 4 weeks'=motivated smokers) ${ }^{10,11}$. b Does not sum up to $100 \%$ because of rounding error. c Chi-squared test for trend. $d \geq 5$ points in the AUDIT-PC ${ }^{12}$. e At least one single use within the last 12 months before the TED-study baseline: cannabis, ecstasy, other designer drugs, natural drugs (e.g. Peyote), cocaine, morphine, heroin or other opiates ${ }^{8}$. f $1475 € /$ month $^{8}$. TED: Tobacco Control in an Urban Emergency Department ${ }^{8}$. SD: standard deviation. ED: emergency department. AUDIT-PC: Alcohol Use Disorders Identification Test-Piccinelli Consumption.

dependent, showed higher motivation to quit smoking and reported lower frequency of harmful alcohol consumption (all $\mathrm{p}<0.05$ ). Retrospective postdiction of abstinence status up to 12 months, for respondents not smoking at the 10 years follow-up rose from $16.3 \%$ at the 1 month follow-up to $36.8 \%$ at the 12 months follow-up while the corresponding abstinence for respondents who reported smoking at the 10 years follow-up rose from $3.2 \%$ at 1 month followup to $11.5 \%$ at the 12 months follow-up (differences between groups: all $\mathrm{p}<0.05$ ). With regard to baseline social influences, tobacco abstainers at the 10 years follow-up compared with self-identified smokers reported more often having a non-smoking partner $(42.9 \%$ vs $21.0 \%, p=0.001)$ and having attained more years of education $(\mathrm{p}=0.035)$.

\section{DISCUSSION}

The long-term follow-up of a randomized controlled trial involving emergency department-initiated tobacco control allowed analyzing both isolated as well as repeated measures of point-prevalence abstinence up to 10 years after the initial intervention. While there was no effect on the single point-prevalence outcome at the 10 years follow-up, evidence obtained from the more integrative modeling approach suggests a small cumulative impact on repeated point-prevalence abstinence across five time-points over the entire course of both studies. Moreover, several smoking-related baseline parameters were significantly associated with continual tobacco abstinence over 10 years follow-up. They included baseline level of nicotine dependence, motivation to quit smoking as well as perceived self-efficacy to quit.

This study is to our knowledge the first attempt to evaluate the impact of ED-initiated tobacco control on 10-year smoking status and to use continual tobacco abstinence as the outcome. Data did not exist on loss to follow-up or effect size for a 10-year follow-up before the Laocoon study. As far as we know, the longest duration of follow-up in previous RCTs involving ED-initiated smoking cessation was 12 months $^{4}$. Considering the null results at the 12 months follow-up of the initial study, the single observation, longer-term result presented here may not be surprising. However, evidence from other medical settings suggests mixed effects of individually-focused tobacco control interventions on long-term tobacco abstinence. In a Chinese smoking cessation clinic abstinence rates rose from $27 \%$ at the 1 year follow-up to $38 \%$ at the 7 years follow-up ${ }^{21}$. Up to 8 years after termination of a 12-month RCT in a dental setting, cessation rates rose by 8 per cent and, although not statistically significant, differences between study arms persisted $(p=0.16)^{22}$. Negative findings occurred in $>2500$ high school smokers 
seven years post-intervention, when motivational interviewing plus telephone counseling showed no impact on quit rates compared to usual care $(14.2 \%$ vs $13.1 \%, p=0.61$; respectively $)^{23}$. Likewise, nonsuperiority occurred in an RCT with $>1600$ study participants that were prescribed the nicotine patch for smoking cessation compared with usual care eight years after study participation (non-smoking rates of $27.6 \%$ compared with $26.4 \%)^{24}$.

Individuals who smoke and present to emergency departments are typically more than a decade younger than patients who smoke and present in the clinical setting, with the latter often already suffering from tobacco-associated disease. Long waiting lines, the ED teachable moment, and the proven efficacy of brief smoking cessation intervention in the ED setting for up to one year are compelling arguments for implementing smoking cessation services into clinical routine in $\mathrm{EDs}^{3}$. The median counseling time in the ED of the TED study was 13 minutes and the median overall initial intervention, together with the four booster phone calls, did not exceed 30 minutes $^{8}$. Thus, overall half an hour of individual face-to-face tobacco counseling in the ED in combination with booster phone calls seems to motivate this harder-to-reach smoking group to at least quit smoking temporarily. Because of the large number of young patients treated in EDs every day, implementation of brief smoking cessation interventions in this setting are likely to have a significant public health impact ${ }^{3}$. On an individual level and independently of age, gender, and educational status, baseline motivation and perceived self-efficacy to quit smoking as well as level of nicotine dependence were prognostic factors of continual tobacco abstinence in the results presented here. These smoking-related factors may be routinely evaluated using paper-based or electronic devices in those ED patients who are eligible for screening and brief intervention and who are not directly transferred to their medical treatment. Information about both baseline parameters helps in tailoring individual smoking cessation, e.g. according to the Clinical Practice Guidelines for Treating Tobacco Use and Dependence $^{25}$.

An additional finding of note is the striking variability not only in smoking status, for those participants who chose to respond to each survey, but also in participants' responsiveness to each survey.
Switching between smoking, non-smoking and studyattrition/study-participation appears to be the norm and continual abstinence (or continual smoking) the exception. Early cessation is no guarantee of longterm abstinence but early relapse is also no guarantee of long-term smoking. It now seems premature to assume that no further follow-up outcome data will be available from a participant who failed to participate in an earlier follow-up assessment. Thus, the idea of capturing one single well-defined and validated study outcome as a proxy for overall success/failure of a tobacco control intervention seems overly pessimistic. Episodes of smoking abstinence increased significantly over time even among smokers in the control group. The significant independent effect of time may reflect the cumulative impact of periodic public health tobacco control campaigns and repeated exposure to other brief clinical interventions. It may also reflect the maturing out of smoking behavior from young adulthood into middle age, independently of a person's individual life course and his/her interaction with the health care system, as well as specific time-period related factors, such as the new availability of e-cigarettes.

\section{Limitations}

Although attrition status was not differentially associated with randomization status, the Laocoonstudy follow-up participants were documentably not representative of the original study sample. Overall, compared to non-participants, participants in the Laocoon study were more often characterized by 'protective' characteristics such as older age (younger age was shown to impede the impact of individual tobacco counseling in different settings $)^{26-29}$, lower nicotine dependence/fewer cigarettes smoked (a strong predictor for cessation success in various settings $)^{26,30-32}$, more years of attained education (a known predictor of both success after smoking cessation $^{33}$ as well as higher study adherence in various settings including tobacco control studies) $)^{26,34-36}$. In univariable comparisons (Table 3 ), this bias was not taken into account and thus, the results have to be interpreted with caution. In the multivariable models however (Table 1), attrition as a potential source of bias was addressed by adjusting for parameters associated with non-response in univariate analysis. Nevertheless, the results presented here have to be regarded as not only deriving from a secondary data 
analysis, but as being the product of exploratory analyses. This is why p-values were not adjusted for multiple testing.

The high rate of loss to follow-up between the 12 months and the 10 years follow-up was to be expected for such a long interval, despite several attempts, including regulatory inquiries, to increase the number of correct addresses and thus the number of potential follow-up participants. A response rate of $23 \%$ (in regard to persons with current postal address) is notwithstanding a significant weakness of this study, that may not be satisfactory eliminated with elaborate analytical approaches.

More confident inferences about modifiable influences on the impact of smoking cessation in the emergency department setting over time await studies that minimize attrition through implementation of more rigorous follow-up protocols. There is furthermore a need for biological validation of smoking status outcomes. While smoking outcomes were biologically validated at the 12 months follow-up of the parent study ${ }^{8}$, this was not feasible during this postal long-term follow-up.

\section{CONCLUSIONS}

Future research in this setting should consider the course of ED patients' compliance/non-compliance evaluated in this specific study setting. The unstable findings involving smoking/non-smoking status highlights the need for analytical approaches that take into account this dynamism of outcome. Research would probably benefit from repeated assessments of 7-day point prevalence smoking status, capturing more adequately the picture of the natural course of the smoking behavior over time. Furthermore, future research should evaluate if the benefit of ED-initiated tobacco control increases with more specifically tailored interventions and more rigorous treatment of tobacco dependence.

\section{REFERENCES}

1. CB Irvin, Wyer PC, Gerson LW, et al. Preventive care in the emergency department, Part II: Clinical preventive services--an emergency medicine evidencebased review. Acad Emerg Med. 2000;7:1042-1054. doi:10.1111/j.1553-2712.2000.tb02098.x

2. Rhodes KV, Gordon JA, Lowe RA, et al. Preventive care in the emergency department, Part I: Clinical preventive services--are they relevant to emergency medicine? Acad Emerg Med. 2000;7:1036-1041. doi:10.1111/j.1553-2712.2000.tb02097.x

3. Bernstein SL, Boudreaux ED, Cydulka RK, et al. Tobacco control interventions in the emergency department: a joint statement of emergency medicine organizations. Ann Emerg Med. 2006;48:e417-e426. doi:10.1016/j.annemergmed.2006.02.018

4. Lemhoefer C, Rabe GL, Wellmann J, et al. Emergency Department-Initiated Tobacco Control: Update of a Systematic Review and Meta-Analysis of Randomized Controlled Trials. Prev Chronic Dis. 2017;14:E89. doi:10.5888/pcd14.160434

5. Murray RP, Anthonisen NR, Connett JE, et al. Effects of multiple attempts to quit smoking and relapses to smoking on pulmonary function. J Clin Epidemiol. 1998;51:13171326. doi:10.1016/s0895-4356(98)00120-6

6. McCarthy DE, Ebssa L, Witkiewitz K, Shiffman S. Paths to tobacco abstinence: A repeated-measures latent class analysis. J Consult Clin Psychol. 2015;83:696-708. doi:10.1037/ccp0000017

7. West R. Tobacco smoking: Health impact, prevalence, correlates and interventions. Psychol Health. 2017;32:10181036. doi:10.1080/08870446.2017.1325890

8. Neuner B, Weiss-Gerlach E, Miller P, Martus P, Hesse D, Spies C. Emergency department-initiated tobacco control: a randomised controlled trial in an inner city university hospital. Tob Control. 2009;18:283-293. doi:10.1136/tc.2008.028753

9. Heatherton TF, Kozlowski LT, Frecker RC, Fagerstrom KO. The Fagerstrom Test for Nicotine Dependence: a revision of the Fagerstrom Tolerance Questionnaire. Br J Addict. 1991;86:1119-1127. doi:10.1111/j.1360-0443.1991.tb01879.x

10. Keller S, Velicer WF, Prochaska JO. Das Transtheoretische Modell - eine Übersicht (The transtheoretical model - a summary). In Keller S, ed. Das Transtheoretische Modell in Forschung und Praxis (The transtheoretical model in research and practice). Freiburg, Germany: Lambertus: 1999: 17-44.

11. Prochaska JO, DiClemente CC, Norcross JC. In search of how people change. Applications to addictive behaviors. Am Psychol. 1992;47:1102-1114. doi:10.1037//0003-066x.47.9.1102

12. Piccinelli M, Tessari E, Bortolomasi M. et al. Efficacy of the alcohol use disorders identification test as a screening tool for hazardous alcohol intake and related disorders in primary care: a validity study. BMJ. 1997;314:420-424. doi:10.1136/bmj.314.7078.420

13. Heatherton TF, Kozlowski LT, Frecker RC, Rickert W, Robinson J. Measuring the heaviness of smoking: using selfreported time to the first cigarette of the day and number of cigarettes smoked per day. Br J Addict. 1989;84:791-799. doi:10.1111/j.1360-0443.1989.tb03059.x

14. Bursac Z, Gauss CH, Williams DK, Hosmer DW. Purposeful selection of variables in logistic 
regression. Source Code Biol Med. 2008;3:17. doi:10.1186/1751-0473-3-17

15. Newcombe PJ, Connolly S, Seaman S, Richardson S, Sharp SJ. A two-step method for variable selection in the analysis of a case-cohort study. Int J Epidemiol. 2018;47:597-604. doi:10.1093/ije/dyx224

16. Miller WR, Rollnick S. Evoking the Person's Own Motivation. In: Motivational Interviewing: Helping People Change. New York: The Guilford Press; 2012: 167-182.

17. Miller WR, Rollnick S. Evoking Hope and Confidence. In: Motivational Interviewing: Helping People Change. New York: The Guilford Press; 2012: 212-230.

18. Jones M, Hockey R, Mishra GD, Dobson A. Visualising and modelling changes in categorical variables in longitudinal studies. BMC Med Res Methodol. 2014;14:32. doi:10.1186/1471-2288-14-32

19. Gabriel KR. Ante-dependence Analysis of an Ordered Set of Variables. Ann Math Stat. 1962;33:201-212. doi:10.1214/aoms/1177704724

20. Kenward MG. A Method for Comparing Profiles of Repeated Measurements. Appl Statist. 1987;36:296-308. doi: $10.2307 / 2347788$

21. Leung DY, Au DW, Lam TH, Chan SS. Predictors of long-term abstinence among Chinese smokers following treatment: the role of personality traits. Asian Pac J Cancer Prev 2013;14:5351-5354. doi:10.7314/apjcp.2013.14.9.5351

22. Nohlert E, Ohrvik J, Tegelberg A, Tillgren P, Helgason AR. Long-term follow-up of a high- and a low-intensity smoking cessation intervention in a dental setting--a randomized trial. BMC Public Health. 2013;13:592. doi:10.1186/1471-2458-13-592

23. Peterson AV, Marek PM, Kealey KA, Bricker JB, Ludman EJ, Heffner JL. Does Effectiveness of Adolescent Smoking-Cessation Intervention Endure Into Young Adulthood? 7-Year Follow-Up Results from a GroupRandomized Trial. PLoS One. 2016;11:e0146459. doi:10.1371/journal.pone.0146459

24. Yudkin P, Hey K, Roberts S, Welch S, Murphy M, Walton R. Abstinence from smoking eight years after participation in randomised controlled trial of nicotine patch. BMJ. 2003;327:28-29. doi:10.1136/bmj.327.7405.28

25. Fiore MC, Bailey WC, Cohen SJ, et al. Treating tobacco use and dependence, clinical practice guideline; Public Health Service. Rockville, MD: U.S. Department of Health and Human Services: 2010.

26. Belita E, Sidani S. Attrition in Smoking Cessation Intervention Studies: A Systematic Review. Can J Nurs Res. 2015;47:21-40. doi:10.1177/084456211504700404

27. Honjo K, Iso H, Inoue M, Tsugane S. Smoking cessation: predictive factors among middle-aged Japanese. Nicotine Tob Res. 2010;12:1050-1054. doi:10.1093/ntr/ntq143

28. Okuyemi KS, Thomas JL, Warren J, Guo H, Ahluwalia JS. Relationship between smoking reduction and cessation among light smokers. Nicotine Tob Res. 2010;12:1005-
1010. doi:10.1093/ntr/ntq138

29. Zethof D, Nagelhout GE, de Rooij M, et al. Attrition analysed in five waves of a longitudinal yearly survey of smokers: findings from the ITG Netherlands survey. Eur J Public Health. 2016;26:693-699. doi:10.1093/eurpub/ckw037

30. Kale D, Gilbert HM, Sutton S. Are predictors of making a quit attempt the same as predictors of 3-month abstinence from smoking? Findings from a sample of smokers recruited for a study of computer-tailored smoking cessation advice in primary care. Addiction. 2015;110:1653-1664. doi:10.1111/add.12972

31. Neves RD, Avila GK, Oliveira FB, Sampaio JAF. Impact of Myocardial Revascularization Method on Smoking Cessation: Coronary Artery Bypass Grafting versus Percutaneous Coronary Intervention. Braz J Cardiovasc Surg. 2017;32:383389. doi:10.21470/1678-9741-2017-0041

32. Okoli CT, Khara M. Smoking cessation outcomes and predictors among individuals with co-occurring substance use and/or psychiatric disorders. J Dual Diagn. 2014;10:9-18. doi:10.1080/15504263.2013.866860

33. Gerber Y, Koren-Morag N, Myers V, Benyamini Y, Goldbourt U, Drory Y. Long-term predictors of smoking cessation in a cohort of myocardial infarction survivors: a longitudinal study. Eur J Cardiovasc Prev Rehabil. 2011;18:533-541. doi:10.1177/1741826710389371

34. Neuner B, Fleming M, Born R, et al. Predictors of loss to follow-up in young patients with minor trauma after screening and written intervention for alcohol in an urban emergency department. J Stud Alcohol Drugs. 2007;68:133-140. doi:10.15288/jsad.2007.68.133

35. Paul M, George PS, Mathew A. Patient and disease related factors associated with lost-to follow-up/dropouts of cervical cancer patients: a study at a Major Cancer Hospital in South India. Asian Pac J Cancer Prev. 2010;11:1529-1534.

36. Strecher VJ, McClure J, Alexander G, et al. The role of engagement in a tailored web-based smoking cessation program: randomized controlled trial. J Med Internet Res. 2008;10:e36. doi:10.2196/jmir.1002

\section{ACKNOWLEDGEMENTS}

WJ McCarthy was supported by National Institute of Health grant U54 CA 143931 during the time that this article was written. We acknowledge further support from the German Research Foundation (DFG) and the Open Access Publication Fund of CharitéUniversitätsmedizin Berlin. The authors thank two anonymous reviewers for their helpful comments on an earlier version of this manuscript.

\section{CONFLICTS OF INTEREST}

The authors declare that they have no competing interests, financial or otherwise, related to the current work. C Spies received funding from Deutsche Krebshilfe (DKH-111507) during the conduct of the present work. C Spies also received funding outside the present work from European Union Seventh Framework research program [FP7/20072013], under the grant agreement No. HEALTH-F2-2014-60246, 
Continued

BioCog. C Spies reports grants outside this work from: Dr F. Köhler Chemie GmbH, AppAdventure, J\&tP Medical Research Ltd., Pharmaceutical Research Associates GmbH, Delcath Systems Inc., INC Research UK Ltd., La Jolla Pharmaceutical Company, Aridis Pharmaceutical Inc., B. Braun Melsungen AG, Drägerwerk AG \& Co. $\mathrm{KGaA}$, Grünenthal $\mathrm{GmbH}$, Infectopharm $\mathrm{GmbH}$, Sedana Medical Ltd., Arbeitsgemeinschaft industrieller Forschungsvereinigungen 'Otto von Guericke' e.V., Berufsverband Deutscher Anästhesisten e.V., Deutsche Forschungsgemeinschaft, Deutsches Zentrum für Luftund Raumfahrt e.V., Einstein Stiftung Berlin, European Society of Anaesthesiology, Gemeinsamer Bundesausschuss, Inneruniversitäre Forschungsförderung, Projektträger im DLR, Stifterverband, WHOCC, Westfälische Wilhelms-Universität Münster/DFG, AbbVie Deutschland $\mathrm{GmbH} \& \mathrm{Co}$. KG, Aguettant Deutschland GmbH, MAQUET Vertrieb und Service Deutschland $\mathrm{GmbH}$, Orion Pharma $\mathrm{GmbH}$, Philips Electronics Nederland B.V., Sintetica $\mathrm{GmbH}$, Baxter Deutschland $\mathrm{GmbH}$, Biotest $A G$, Cytosorbents Europe $\mathrm{GmbH}$, Edwards Lifesciences Germany $\mathrm{GmbH}$, Fresenius Medical Care, Grünenthal $\mathrm{GmbH}$, Masimo Europe Ltd., Medtronic GmbH, Pfizer Pharma PFE GmbH, European Commission, Bundesministerium für Umwelt, Naturschutz und nukleare Sicherheit. C Spies also reports personal fees from Georg Thieme Verlag outside this work. In addition, C Spies has a patent 102014215211.9 pending, a patent Application No. PCT/EP2015/067730 pending to Graft Gesellschaft von Architekten $\mathrm{mbH}$, and a patent Application No. PCT/ EP2015/067731 pending to Graft Gesellschaft von Architekten mbH. The rest of the authors have also completed and submitted an ICMJE form for disclosure of potential conflicts of interest.

\section{FUNDING}

The Laocoon study was financed by the German Cancer Foundation (Deutsche Krebshilfe), Bonn, Germany (Grant DKH-111507), and by institutional resources of the Charité-Universitätsmedizin Berlin.

\section{PROVENANCE AND PEER REVIEW}

Not commissioned; externally peer reviewed. 